\title{
Recurrence of Anti-Neutrophil Cytoplasmic Antibody-Associated Vasculitis in Appropriately Immunosuppressed Renal Transplant Patients: A Discussion of Two Cases
}

\author{
Frank J. O'Brien ${ }^{a}$ Ahad Abdalla ${ }^{b}$ Limy Wong ${ }^{a}$ Carol A. Traynor ${ }^{a}$ \\ Paul Cheriyan $^{a}$ Hong Kwan Kok ${ }^{a}$ Liam Casserly ${ }^{b}$ Anthony Dorman ${ }^{a}$ \\ Peter J. Conlon ${ }^{a}$ \\ a Department of Nephrology, Beaumont Hospital, Dublin, and 'bepartment of Nephrology, \\ Mid-Western Regional Hospital, Limerick, Ireland
}

\section{Key Words}

Anti-neutrophil cytoplasmic antibody vasculitis $\cdot$ Renal transplantation - Disease recurrence

\begin{abstract}
Background: Granulomatosis with polyangiitis (GPA) (formerly known as Wegener's granulomatosis) is a multisystem autoimmune disease of unknown aetiology. Renal disease manifests as a crescentic glomerulonephritis, with varying degrees of renal failure. Ten percent of patients progress to end-stage kidney disease. Relapse of GPA in renal transplant patients is rare, with a rate of 0.09 relapses per patient per year. Patients and Methods: We describe two cases of GPA relapse in immunosuppressed renal transplant patients. Results: These patients presented with new-onset graft disfunction, having previously had an uncomplicated posttransplant course. Both patients were on appropriate doses of immunosuppressive agents at the time of relapse, with therapeutic target levels of tacrolimus. We describe the background history and management of both patients. Conclusion: The cases described inform us that although recurrence of anti-neutrophil cytoplasmic antibody vasculitis in transplant patients is rare, it should remain on our list of differential diagnoses in allograft disfunction.
\end{abstract}




\section{Background}

Wegener's granulomatosis or granulomatosis with polyangiitis (GPA) is a multisystem autoimmune disease of unknown aetiology. Its hallmark features include necrotizing granulomatous inflammation and pauci-immune vasculitis in small and medium-sized blood vessels of the respiratory tract and renal tract [1]. GPA is one of the anti-neutrophil cytoplasmic antibody (ANCA)-associated vasculitides [2, 3]. The incidence and prevalence of GPA in the United Kingdom is estimated at 10.2 and 250 cases per million population, respectively [4].

GPA has a spectrum of clinical presentations and more than $75 \%$ of patients will develop renal disease. Renal involvement manifests as a crescentic necrotizing glomerulonephritis, which may be associated with renal failure $[5,6]$. Current treatment recommendations in GPA depend on the severity and activity of disease, and include a combination of cyclophosphamide, glucocorticoids and in certain circumstances therapeutic plasma exchange [7-10].

Relapse of ANCA vasculitis in renal transplant patients is rare. The rate of relapse after transplantation is approximately 0.09 per patient per year [11]. In a study that ran from 1980 to 1995, the course of 13 patients with end-stage kidney disease (ESKD) due to GPA was described. One of the patients developed recurrent disease in the transplanted organ [12]. A post-kidney transplant relapse rate of $17.3 \%$ was derived by groups in Sweden and the United States, combining the respective groups' experience of 101 and 26 patients, respectively. Renal involvement occurred in 12 of 22 relapse cases (55\%) and resulted in graft loss or declining function in 4 of 12 . This equates to approximately an $18 \%$ relapse rate.

In general, reports of relapse rates and severity of ANCA vasculitis following kidney transplant are low. Here we describe two separate cases of GPA relapse in appropriately immunosuppressed renal transplant patients.

\section{Cases}

Case 1

Our first case initially presented aged 14 in 2001 with a two-week history of vague ill health, back pain and intermittent haematuria. She was noted to have acute renal failure with both blood and protein in her urine; creatinine was $280 \mu \mathrm{mol} / \mathrm{l}$.

The patient was cytoplasmic ANCA (cANCA) positive and proceeded to renal biopsy. This confirmed necrotizing crescentic glomerulonephritis, consistent with GPA. She was commenced on high-dose intravenous methylprednisolone for three days followed by oral prednisolone and pulsed intravenous cyclophosphamide once per month for three months. She required peritoneal dialysis for 3-4 weeks and was discharged, dialysis free with an estimated glomerular filtration rate of $24 \mathrm{ml} / \mathrm{min} / 1.73 \mathrm{~m}^{2}$. She remained on oral azathioprine as maintenance therapy.

She progressed to ESKD and was transplanted in September 2002. Her anti-proteinase 3 (anti-PR3) level was $<5 \mathrm{IU} / \mathrm{ml}$ at the time of transplantation. She was well for the following seven years with a baseline creatinine of $12 \mu \mathrm{mol} / \mathrm{l}$, maintained on tacrolimus, azathioprine and prednisolone.

In 2009 the patient was noted to have an increased creatinine of $200 \mu \mathrm{mol} / \mathrm{l}$, with arthralgia and right-sided episcleritis. Her anti-PR3 antibody level was $26 \mathrm{IU} / \mathrm{ml}$, increased from a baseline value of $<5 \mathrm{IU} / \mathrm{ml}$. At this time she was on prednisolone $5 \mathrm{mg}$ once per day, tacrolimus $2 \mathrm{mg}$ twice per day and azathioprine $50 \mathrm{mg}$ once per day. Her tacrolimus level was $6 \mathrm{ng} / \mathrm{ml}$. She had a transplant renal biopsy. This showed features of pauci immune 
necrotizing and crescentic glomerulonephritis, consistent with a recurrence of GPA (fig. 1, fig. 2).

Her creatinine continued to rise, and her immunosuppression was further increased to include rituximab $1 \mathrm{~g}$ intravenously once per week for two weeks as treatment for relapse. It was thought that further courses of cyclophosphamide would not be appropriate, given her previous exposure to this drug, and given the risk of infertility. We also commenced a threeday course of intravenous methylprednisolone and changed her from azathioprine to mycophenolate.

This patient did not achieve remission; her creatinine rose to $280 \mu \mathrm{mol} / \mathrm{l}$ and her urine remained active. She was commenced on therapeutic plasma exchange, receiving a total of five four-litre exchanges over ten days. She was commenced on cyclophosphamide $15 \mathrm{mg} / \mathrm{kg}$ once per month for three months. This regime was based on a modified version of the EUVAS (European Vasculitis Study Group) protocol [8].

She achieved remission, and creatinine fell to $180 \mu \mathrm{mol} / \mathrm{l}$, with a normalisation of her urinary sediment. She continues to be maintained on tacrolimus, mycophenolate and prednisolone (fig. 3).

Case 2

A 64-year-old lady presented with ESKD in 2001. Her primary physician noted her to be hypertensive and to have a serum creatinine of $400 \mu \mathrm{mol} / \mathrm{l}$. She had no clinical features of systemic vasculitis. She had a history of preeclampsia during a previous pregnancy. Urinalysis revealed $3+$ blood and $3+$ protein. Ultrasound revealed small kidneys measuring $8 \mathrm{~cm}$ bilaterally. Perinuclear ANCA (pANCA) was positive with myeloperoxidase (MPO) specificity at a titre of $>700 \mathrm{IU} / \mathrm{ml}$. She did not undergo renal biopsy.

The patient commenced haemodialysis three times per week, with a presumptive diagnosis of ESKD secondary to pANCA-associated vasculitis. She did not receive any specific systemic treatment, as she did not have any features of active vasculitis. Her clinical condition improved and she remained on haemodialysis for the following six years.

She received a deceased donor renal transplant in January 2007. Her anti-MPO antibody level was $<5 \mathrm{IU} / \mathrm{ml}$ at time of transplant. She was discharged on maintenance tacrolimus 1.5 mg b.d., and mycophenolate $500 \mathrm{mg}$ b.d. She was discharged on a steroid-free regime. This was based on emerging evidence at the time of the potential benefits of a steroid avoidance immunosuppressant regime [13].

In 2009 creatinine rose from a baseline level of $150 \mu \mathrm{mol} / \mathrm{l}$ to $200 \mu \mathrm{mol} / \mathrm{l}$ in the setting of an unresolving lower respiratory tract process with pulmonary infiltrates. This rise in creatinine occurred over 8 weeks. This was preceded by newly noted positive urinalysis, 3+ protein, 3+ blood. At this time she was on mycophenolate $250 \mathrm{mg}$ b.d. and tacrolimus $0.5 \mathrm{mg}$ b.d. Her tacrolimus levels were between 4 and $5 \mathrm{ng} / \mathrm{ml}$ at this time. Her presentation was associated with pANCA positivity, with an anti-MPO antibody level of $640 \mathrm{IU} / \mathrm{ml}$.

A transplant biopsy was performed which revealed pauci immune necrotizing and crescentic glomerulonephritis. This was consistent with GPA recurrence (fig. 4).

She was switched from mycophenolate to azathioprine, and was treated with pulsed intravenous methylprednisolone $1 \mathrm{~g}$ for three days. She was continued on maintenance oral prednisolone $7.5 \mathrm{mg} /$ day. She did not receive cytotoxic chemotherapy or plasma exchange. It was felt this patient's recurrence of GPA was due to her steroid-free immunosuppressive regime. She was switched from maintenance low-dose mycophenolate to azathioprine 100 $\mathrm{mg} /$ day; she was intolerant of higher doses of mycophenolate. Her creatinine returned to baseline over the following seven days (fig. 5). 


\section{Discussion}

These cases describe the rare recurrence of ANCA vasculitis/GPA in appropriately immunosuppressed transplant patients.

In previous studies, it was found that graft outcomes were more favourable if transplantation occurred at least a year post-induction of remission. It was also found that the presence of circulating ANCA at the time of transplantation was associated with increased severity of vasculopathy in subsequent transplant biopsies [14]. The cases described above did not have these high-risk features. At the time of transplant, both had undetectable levels of ANCA, and both were transplanted at least one year after remission. This study also found that graft survival in those with an underlying diagnosis of ANCA-associated vasculitis was similar to graft survival in those with other causes of ESKD.

Relapse of ANCA vasculitis in non-transplant patients was noted to be more common in patients treated with mycophenolate than in patients treated with azathioprine [15]. Although we cannot directly extrapolate the findings of the IMPROVE trial to transplant patients, it does raise the possibility that patients with ESKD secondary to ANCA vasculitis should be maintained on azathioprine instead of mycophenolate.

The two cases described above emphasise the importance of regular follow-up of transplant patients, and informs us that although recurrence of ANCA vasculitis in transplant patients is rare, it should remain on our list of differential diagnoses in allograft disfunction.

\section{References}

1 Jenette JC, Falk RJ, Andrassy K, Bacon PA, Churg J, Gross WL, et al: Nomenclature of systemic vasculitides. Proposal of an international consensus conference. Arthritis Rheum 1994;37:187-192.

$\checkmark 2$ Stone JH: Limited versus severe Wegener's granulomatosis: baseline data on patients in the Wegener's granulomatosis etanercept trial. Arthritis Rheum 2003;48:2299-2309.

-3 Leavitt RY, Fauci AS, Bloch DA, Michel BA, Hunder GG, Arend WP, et al: The American College of Rheumatology 1990 criteria for the classification of Wegener's granulomatosis. Arthritis Rheum 1990;33:1101-1107.

-4 Watts RA, Lane SE, Scott DG, Koldingses W, Nossent H, Gonzalez Gay MA, et al: Epidemiology of vasculitis in Europe. Ann Rheum Dis 2001;60:1156-1157.

5 Seo P, Stone JH: The antineutrophil cytoplasmic antibody associated vasculitides. Am J Med 2004;117:3950.

6 Fauci AS, Haynes BS, Katz P, Wolff SM: Wegener's granulomatosis: prospective clinical and therapeutic experience with 85 patients for 21 years. Ann Intern Med 1983;98:76-85.

7 Mukhtyar C, Guillevin L, Cid MC, Dasgupta B, de Groot K, Gross W, et al: EULAR recommendations for the management of primary small and medium vessel vasculitis. Ann Rheum Dis 2009;68:310-317.

8 Jayne D, Rasmussen N, Andrassy K, Bacon P, Tervaert JW, Dadoniene J, et al: A randomized trial of maintenance therapy for vasculitis associated with antineutrophil cytoplasmic autoantibodies. N Engl J Med 2003;349:36-44.

-9 Walsh M, Merkel PA, Mahr A, Jayne D: Effects of duration of glucocorticoid therapy on relapse rate in antineutrophil cytoplasmic antibody-associated vasculitis: a meta-analysis. Arthritis Care Res (Hoboken) 2010;62:1166-1173.

10 Pusey CD, Rees AJ, Evans DJ, Peters DK, Lockwood CM: Plasma exchange in focal necrotizing glomerulonephritis without anti-GBM antibodies. Kidney Int 1991;40:757-763.

11 Allen A, Pusey C, Gaskin G: Outcome of renal replacement therapy in antineutrophil cytoplasmic antibodyassociated systemic vasculitis. J Am Soc Nephrol 1998;9:1258-1263.

12 Wrenger E, Pirsch JD, Cangro CB, D’Alessandro AM, Knechtle SJ, Kalayoglu M, et al: Single-center experience with renal transplantation in patients with Wegener's granulomatosis. Transpl Int 1997;10:152-156.

13 Luan FL, Steffick DE, Ojo AO: Steroid-free maintenance immunosuppression in kidney transplantation: is it time to consider a standard therapy? Kidney Int 2009;76:825-830.

14 Little MA, Hassan B, Jacques S, Game D, Salisbury E, Courtney AE: Renal transplantation in systemic vasculitis; when is it safe? Nephrol Dial Transplant 2009;24:3219-3225. 
Case Reports in

Nephrology and Urology

\begin{tabular}{l|l}
\hline Case Rep Nephrol Urol 2013;3:16-21 \\
\hline DOI: $\underline{10.1159 / 000347142}$ & $\begin{array}{l}\text { ○ } 2013 \text { S. Karger AG, Basel } \\
\text { www.karger.com/cru }\end{array}$ \\
\hline
\end{tabular}

O'Brien et al.: Recurrence of Anti-Neutrophil Cytoplasmic Antibody-Associated Vasculitis in Appropriately Immunosuppressed Renal Transplant Patients: A Discussion of Two Cases

15 Hiemestra TF, Walsh M, Mahr A, Savage CO, de Groot K, Harper L, et al: Mycophenolate mofetil versus azathioprine in anti neutrophil cytoplasmic antibody-associated vasculitis: a randomised controlled trial. JAMA 2010;304:2381-2388.

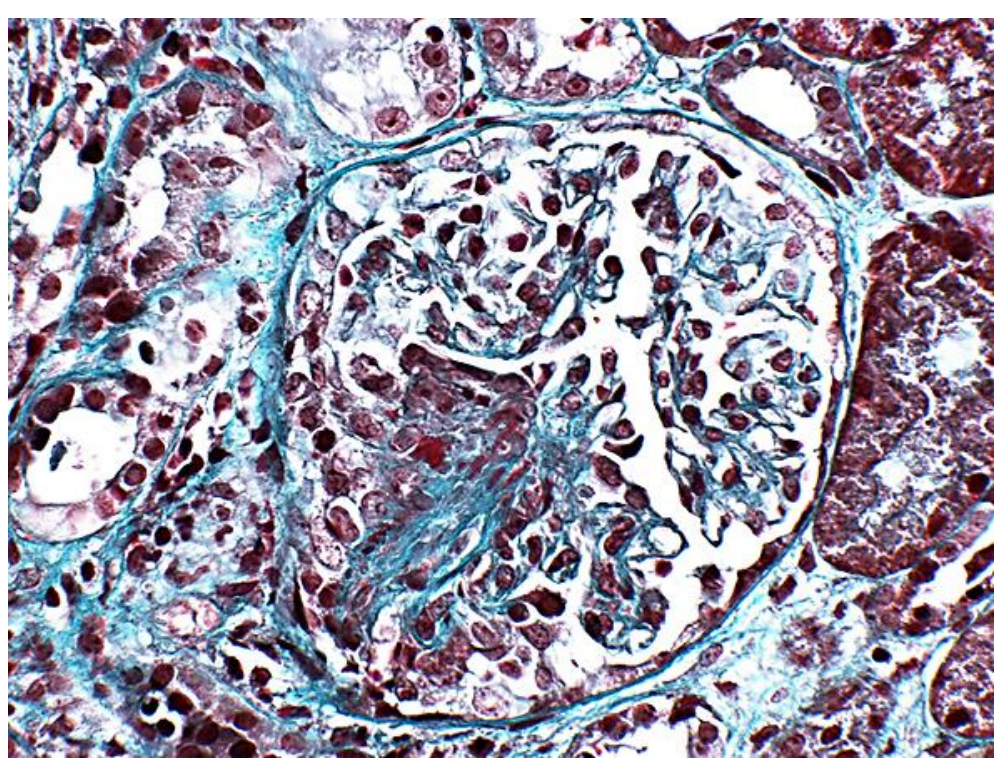

Fig. 1. Transplant renal biopsy of patient 1 showing characteristic crescentic features of ANCA vasculitis.

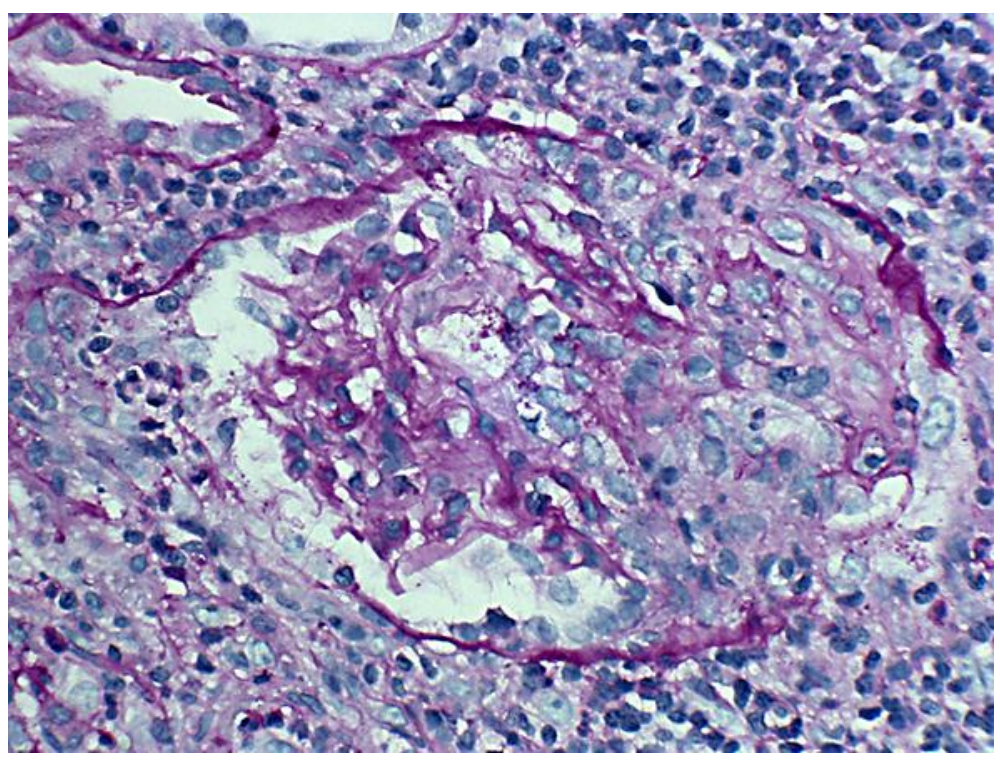

Fig. 2. Characteristic features of ANCA vasculitis with crescent formation (PAS stain). 
Case Reports in

Nephrology and

Urology
Case Rep Nephrol Urol 2013;3:16-21

DOI: $\underline{10.1159 / 000347142}$

O'Brien et al:: Recurrence of Anti-Neutrophil Cytoplasmic Antibody-Associated Vasculitis

in Appropriately Immunosuppressed Renal Transplant Patients: A Discussion of Two Cases

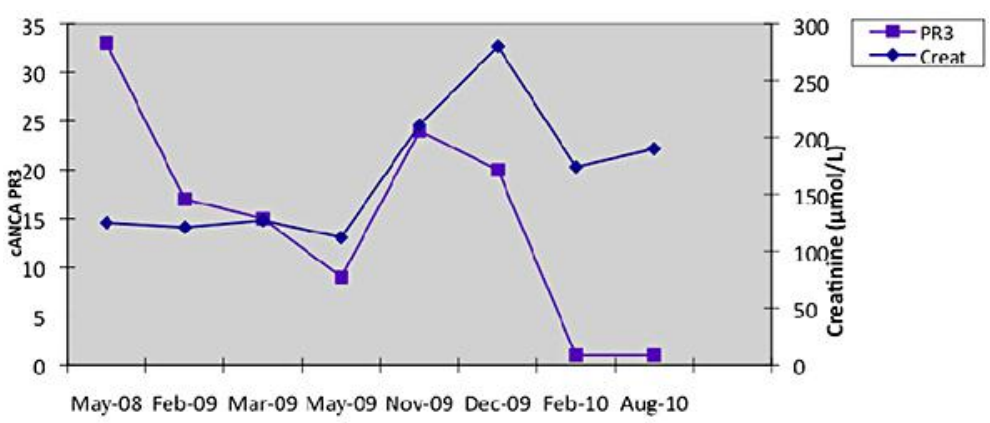

Fig. 3. Chart highlighting changes in creatinine and cANCA PR3 levels over the course of the recurrence.

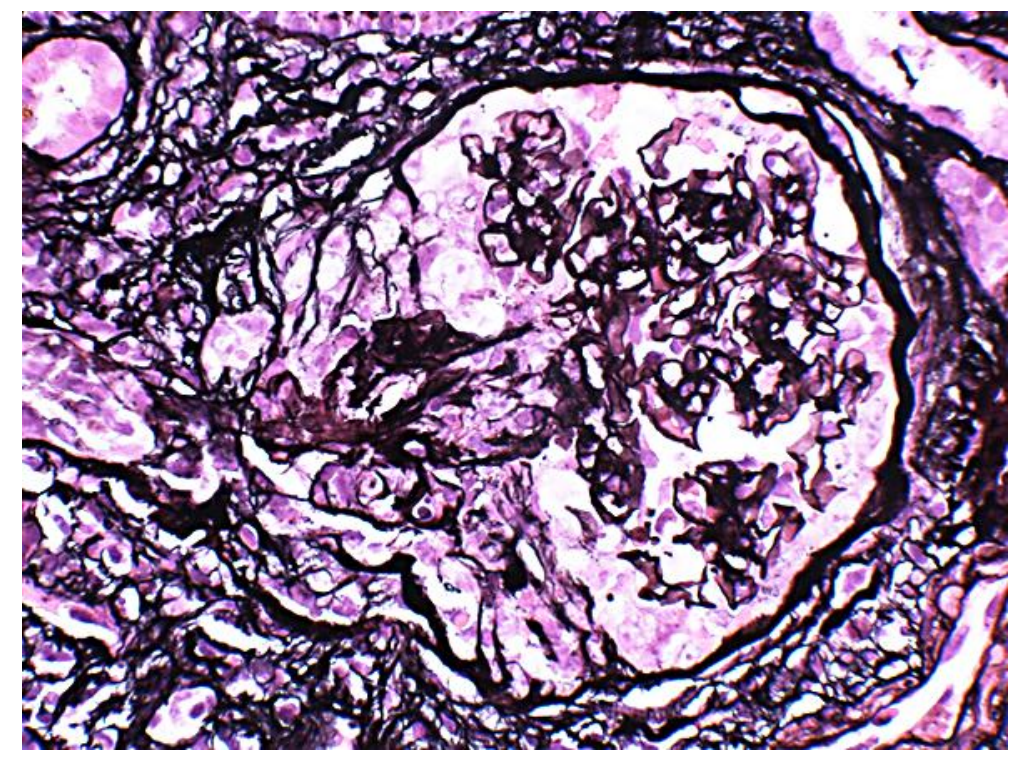

Fig. 4. Crescent formation (Silver stain)

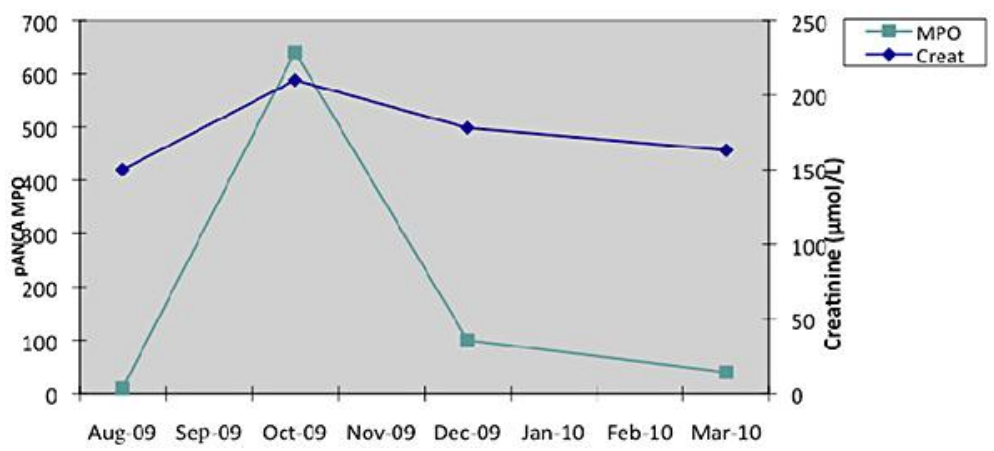

Fig. 5. Chart highlighting changes in creatinine and pANCA MPO levels over the course of the recurrence. 